Dedicated to my Dad

Pieter

19-04-1922 - 18-04-2004

'Recte faciendo neminem timeas'

\title{
What about choice for a change?
}

There is no easy way to explore or to grasp the whole of the multidisciplinary nature of choice and change. Here, at the simplest level, human choice is taken as creating a change and in corollary, change implies that a choice has been made. However, in reality choice and change together weave a complex pattern across the breadth of human fields of knowing and defy attempts to excise them for observation in any discreet sense. Pulling the threads of choice and change decontextualises them and renders them less than they are from within the fabric of human existence. Yet there must be some way to study them. This essay seeks to maintain choice and change, in situ, and to adopt broad ranging perspectives and focal points in examining them. The intention is to illuminate the threads choice and change weave and to interrupt the patterns of choice in the interests of change in a range of areas, including education. It will also incorporate some new threads into emerging choice and change in the future.

An opening thought is offered as an initial lens: the knowledge economy, for all its benefits has created a problem with regard to choice. As Hargreaves (2003, p.38) observes, '...choice for most people is inversely related to significance; ...most people only have choice only of life's inessentials.' Choice is endlessly available, overwhelmingly so, but increasingly only for things that don't ultimately matter in the substance of life. This has implications for those growing up in this era, for their education, and for the future they will be creating. Most present adults would support the development of active citizenship in young people, but being a 'solid citizen' is no longer possible or appropriate in today's society. Citizens today need to be fluid, proactively on the move. It is said that 'all that is solid melts into air' (Berman, 1988, using the words of Marx), leaving young people with little that is tangible to grasp in shaping their world. They have choice in every minor detail that floats by, but does this lead to opportunities and skills to change things that matter and to influence the formation of a better world? In taking an eclectic approach to examine the 'state of play' with regard to choice and change, a question that invites reflection is this: What will be the legacy of young people's 
choices in today's world for the realities of tomorrow? The journey here begins with looking at choice and change through a broad sociological lens and moving in increasingly tighter focal points to come to rest on young people as biological and cultural individuals. It also inquires into how education and its practices can hinder or support meaningful and significant choices by young people towards their development into 'citizens of the world' who can make a difference.

\section{F-stop: society and choice}

Sociologists present an intriguing picture of the consumer driven economy where the freedom to choose is considered a basic human right... as long as it makes money. For example, according to Barber (1995, p.87), free choice and free markets in the information services sector could lead to 'a monopoly more perilous to liberty than any dreamed of by mineral and durable goods megamonopolists'. One could wonder if manipulating a demand for choice in the masses to service ambitions for individual wealth in a few could be considered to fulfil any human right in a broad social sense. Barber (1995, p.86) asks, 'How can the public be represented by markets that privilege individual consumption, taken consumer by consumer, but have no way of representing public goods - what individuals share and thus what makes them more than consumers?' He scathingly observes that markets empower individuals to choose (Barber, 1995), but that this choice is skewed: choice is about what to buy and consume but never about choosing to participate in the consumer economy or not. When individual profit is the sole criterion for measuring the value of goods and services and 'the money hooligans are princes' (Barber, 1995, p.98), public empowerment is to the degree of end-user choices of style - the insignificancies of colour and flavour, for example - while everything else becomes a matter of passive, uncritical consumption. Goods and services are standardised through the real power of the market and 'good value' choices for consumers come to be only about optional extras (Hargreaves, 2003).

In this individualised society (Bauman, 2001), choice is seductive as it gives consumers the feeling, if not the substance, of power. Ready to do anything to avoid the disquieting disconnection (Friedman, 1999) that individualism brings, consumers can - even knowingly at times - take comfort in the illusion of choice because it gives them a sense of control over their lives and a sense of group belonging. That this belonging is limited to choices amongst cosmetic 'extras' within the same set of goods and services is irrelevant. The field is given 
and it is 'cool' - even necessary - to conform (Bauman, 2000): to wear the same brands although choosing different individualising details like colour is expected, and to eat at the same place where selecting different sauces gives the stamp of individual choice. As Friedman (1999, p.240) explains, 'People are firm believers in free will. But they choose their politics, their dress, their manners, their very identity, from a menu they had no hand in writing.' It could be said they collude in their own delusion, their 'air' rather than any 'solidity' shaping their apparent power. As such, they are also readily available for shaping by others; for grooming by the 'commercial conspiracy’ (Bauman, 2000) of the market.

Once upon a time, markets incited desire in would-be consumers. The etymological roots of 'desire’ are ‘de sider; of the stars' (Whyte, 2001). To have a desire in life meant to keep a star in sight, to hold to an ideal of what could not yet be fully imagined. In search of a better life, the promise of pleasure and fulfilment (Bauman, 2000) in the form of the latest goods, such as relief from work with labour-saving devices, had people scrimping and saving so they could eventually satisfy their desire. In today's economy, such a tactic takes too long and is too spasmodic. Hungry markets now need a shorter timeframe and continuous buying, and have moved to focusing on more immediate wish gratification (Bauman, 2003). Consumers feel immediate satisfaction and tangible power in being able to grant themselves their wishes, even if it is only in something like choosing which way to have their coffee served out of the options presented. The commercial conspirators aim for 'fast arousal and quick extinction of wishes’ (Bauman, 2003). As Bauman (2003, p.12) explains, 'The brevity of their life expectation is the wishes' major asset, giving them an edge over desires. Surrendering to wishes, unlike following a desire, is known to be but momentary, bearing the hope that it will leave no lasting consequences that could bar further moments of joyful ecstasy.' Continuous wish fulfilment works for the market in keeping consumer spending up and apparently works for the 'empowered' consumer in abrogating responsibility for compulsive 'spur of the moment' choices manufactured behind the scenes by the market. In Bauman’s (2000, p.87) view, 'Consumer choice is now a value in its own right; the activity of choosing matters more than what is being chosen.' The illusions and delusions of choice thus have economic significance but not lasting individual significance. However, as Friedman (1999, p.240) points out, there is also an 'enormous social significance' to be considered.

Despite the 'knowledge' economy, wishful people are becoming fatalistic consumers who 'use up' the world rather than 'knowledgeable' producers whose destiny is to make the world (Bauman, 2000). To compensate for their insecurities and powerlessness in a changing world, 
they hide in illusions of power (Bauman, 2000) through exercising individual choice for personal gain. Barber (1995, p.221) warns that construing choice in this way works to sever the 'freedom' of buying and selling from people's rights to 'choose in common their common good or the social character of their shared world.' He sees widening individual choices as shrinking social choices and forcing 'infrastructural changes [that] no public community ever consciously either selects or rejects (Barber, 1995, p.220). Friedman (1999) adds that people are naïve about and unaware of the constraints that guide and limit their choices and that this has social and cultural, as well as economic, implications. Using the apparently limitless choice on the internet reflects this; few people know how to find and choose information that is not presented through the constraining lenses of commercial search engines and directories. Yet this state of affairs is also a choice, albeit unaware by most. Hargreaves (2003), for example, is upfront in stating that governments, the representatives of the people, trade off security for removing constraints on a free market. They increasingly move the onus of support and protection from the public to the private sphere, creating insecurity on a broad scale. He points out, however, that this is 'not an unavoidable state of being. It is a political choice in the knowledge society’ (Hargreaves, 2003, p.42).

Rather than being concerned about such quasi-'empowerment' through choice, Bauman (2001) believes people's focus should be on emancipation. To him, the real choice is between the expansive and inclusive option of taking up individual and shared responsibility to create an autonomous society, and the limiting and exclusive option of seeking shelter through 'hiding from the requisites of responsible choice' (Bauman, 2000, p.213) by not accepting ownership of the outcomes of individual and shared actions. This is a difficult choice. As Barber (1995, p.220) puts it, 'The ideology of choice seems to liberate the body ... but fatally constricts the possibility of real freedom for the soul (you cannot choose not to choose, that is, you cannot choose to withdraw from the market or reject the demands of the body)'. However, Bourdieu (1990) emphatically states that, 'Freedom is not something given: it is something you conquer - collectively.' In a mind-over-matter (of the body) stance, he believes that freedom can be claimed, but notably he says ‘collectively'; in other words, as a social act of responsibility for the group.

In a world of consumerism bent on private rather than public discourse, the question for those activists and emancipists who would conquer freedom by choosing collective social responsibility becomes that of how to produce the 'public goods' and the common weal that Barber (1995) spoke of. Barber (1995, p.244) himself suggests that democracy 'must secure 
an alternative form of choice that permits common choosing as a remedy to the inadvertent social consequences of individual choosing'. The next question that goes begging asks if some ameliorative democratic form of common choosing is enough of a remedy. A demos formed of political representation, for example, does not involve the same quality of choice as a democracy based on consensual diversity (Ogilvie, 2004b). Is some deeper change of choice needed to find a truly empowering cure, or is the malaise of the market something that consumers simply feel powerless to do anything about and so retreat into the sheltering false power of insignificant choices? To become socially responsible as a choice of free will and to make democracy truly work, a consideration of individual responsibility is necessary.

The notions of 'individual' and identity are not easy to grasp when solid melts into air. As the world dissolves, people too are losing their edges, with identity becoming more horizontally characterised than vertically defined, as Friedman (1999) frames it. In contrast to traditional hierarchical, that is vertical, arrangements, he posits that identity is becoming more fluid and open to choice. Through never-ending choice, consumers are able to style their identities with horizontal breadth through the messages of their wardrobe, their car, their house, their relationships, their work and so on, ad infinitum. Individual identity spreads out into an amorphous mass of masks to put on or take off according to circumstance. Indeed the 'democratic citizen' costume can see consumers conscientiously voting or waving placards at a protest, but there is a limit to how long and in what ways it can be worn to serve as disguise for people fearful of disconnection. The various identities are, in essence, more concerned with sheltering the individual than with acting for the good of the group. When responsibility for actions becomes an issue, such as conscientiously upholding the choices-in-common of the demos, consumers can move onto another identity. To take the risk of being significantly different is unacceptable to most. They are motivated away from insecurity and prefer to choose some kind of conforming face to avoid confronting their own which may not 'fit'. Those, however, who have the courage to refuse to accept the apparent inevitability of 'can't do anything about it' make a choice that is significant. In accepting personal responsibility for social actions, they become 'air-eaters', taking their sustenance and power from ambiguity and ambivalence. Instead of avoiding these, they choose the deep personal and individual change of becoming immersed in them. However, being a consumer society, there is a price for facing the fear of such an immersion. 


\section{Focal point: exile}

To describe this move to conquering freedom through choosing social responsibility and becoming immersed in change, a short personal parable is referred to as an allegory. It comes of a period of reflection on the writing of Tester (2004) about the sociologist, Zygmunt Bauman and his notions of exile:

Late in his tender seventeenth year, my father made the moral choice of choosing his destiny rather than succumbing to a utilitarian fate of collaboration and survival. His small country had been invaded, overrun by a mighty force determined to impose a new order. His response, true to his family motto, was to be 'upright' and in that stance, he had 'nothing to fear'. He and his people chose the dignity of being human in refusing their surrender to what seemed to be the inevitable. Instead, they changed; they adapted. They went underground, going voluntarily into exile to resist the invader, there together to conspire their own complex ways of transforming the ambivalence of a world turned upside down through fear and hunger into hope and faith for humanity.

The example of these people's lives is told in salute to their courage in risking choice and accepting the responsibility of uncertain self-determination. Although these events took place more than sixty years ago during a world war, they have parallels in today's economy. Rampant market forces might be seen as overrunning people’s lives, leaving them feel invaded, sacrificed to the power of the dollar which supposedly speaks in their name. Consumers can feed their insecurity by going along with the new order as fearful and passive collaborators, but they also can choose not to surrender their integrity. They can choose to bear the price, that of exile from the familiar and comfortable choices. The price is more than 'normality' in life; the price of autonomous and social human being is an unveiled awareness which perceives that the normal world is not 'natural and inevitable' (Tester, 2004) and that 'many of our 'free choices' are dictated by social forces or hidden norms that we are totally unaware of, or are exercised within limits and boundaries that we never think about' (Friedman, 1999, p.10). The exile must see through the illusions of being free and being able to choose freely.

The body that Barber (1995) referred to is indeed not free; it is socially overwritten with what Bourdieu (1990) names the 'habitus', a system of acquired dispositions that proscribe life through habit - habits acquired as a result of or through the apparently natural actions of the 
dominant agents, which in today's case are the market forces. The habitus is mediated through body, through language, through conception (Ogilvie, 2004b) and is comprised of Friedman's (1999) 'social forces' and 'hidden norms'. It is what Bourdieu (1990, p.14) terms, the 'unchosen principle of so many choices' that demonstrates that 'the choice of [a] philosophy of free choice isn’t randomly distributed'. Free choice now belongs predominantly to Barber’s (1995) 'money hooligans'. Rejecting the 'demands of the body' he spoke of and claiming freedom of choice in thought and feeling, in communication and action, is the challenge of those whose free will lifts the veils of habitus. New identities of self and social responsibility have the opportunity to arise, dissolving the body rendered of solid normality and producing the changeable world of air. Free choice for the resistance fighters in the story belonged to the invading powers. Their bodies were constrained and manipulated by fear and hunger created by these dominators, but in going into exile on moral grounds to reclaim their free will and to establish new identities of activism, they rejected those demands of the flesh. Now many years later, Tester (2004) writes that Bauman considers the common experience of the present is also of exile; of displacement from the self, others and the world around. For those who choose a different, emancipist path to reclaim their dignity from the habitus of normality, exile becomes a journey further away but, as Tester (2004) writes, Bauman proposes that 'exile should be confronted actively as an opportunity for the practice of a distinctly human being in the world' (Tester, 2004, p.8). Exile can be a chosen vocation, as Bauman (in Tester, 2004) puts it, of transforming the given through free will and choice into the consciously created. Ambivalence will always exist in the society of air, but the exile in coming home chooses to live with fluid change and to accept responsibility for self and other.

Interrogating reality is not for the faint hearted. The exile is no longer in touch with the codes of ethics that ruled vertically integrated times. Floating on air, rigid bonds and boundaries are difficult to maintain. Yet the self-authorising exile who chooses to accept self and social responsibility needs to connect with and relate heterarchically to others. The exiles in the story used their own moral authority as the basis of relationship to guide their actions. For them, being 'upright' for themselves, collectively and individually, made them 'fearless' in doing what they could to secure a freely-chosen destiny for their people. No one compelled them and nothing propelled them but their moral force. Similarly today, the emancipist voluntarily in exile from the normalising habitus can choose to act from an individual moral position that supports the group. Ogilivie (2004a), for example, proposes that a better type of world and a better way of life is possible through meek and consensual, helpful individualism, based on a moral position powered by love instead of money. He notes that, 'The challenge is 
to change the way we are, beginning with the way in which we conceptualise the contexts that give meaningful purpose to, and/or logical reason for, the type of life we live' (Ogilvie, 2004a, p.14) and adds that, 'The choice is free, but choosing is compulsory' (Ogilvie, 2004a, p.15). Consumers can choose to go along with the habitual order or can choose a more productive way of exile and emancipation. In taking one path or another, a choice is made, regardless of awareness of having made a choice. Those who pierce the veils of habitus but who choose to collaborate with it might be seen as morally selfish. Indeed, Bauman (2000, p.215) goes further to state that, 'Whoever willingly or by default partakes of the cover-up or, worse still, the denial of the human-made, non-inevitable, contingent and alterable nature of social order ....is guilty of immorality - of refusing to help a person in danger.'

One avenue of resistance used by the exiles of the story was to provide, at great danger to themselves, an 'underground' escape route for people 'on the surface' in danger of persecution by the invaders. Another was to foil the power of the dominant agents by compromising their fuel, much like the present day equivalents whose meek and consistent choice of love (Ogilvie, 2004a) acts as a foil to the power of the market that fuels today's life. According to Bauman (2001), to choose to be 'for the Other', as exiles did and still do, is to choose love over the 'using-up' of consumption. He purports that use annihilates the other but, 'To love, on the contrary, means to value the other for its otherness, to wish to reinforce it in its otherness, to protect that otherness and make it bloom and thrive' (Bauman, 2001, p.165-6). Further, Tester (2004, p.145) relates that Bauman proposes that morality signals freedom and is therefore 'a mark of humanity and a responsibility as opposed to a duty'. The moral and freely-chosen choice of love, of the giving of value to the other, by refusing surrender to a perceived duty of consuming can thus be seen as an act of responsible human being. Individuals work and live with the other in numerous ways, so the next 'stop' will examine the organisation as a system and one possible way in which responsible human beings might relate to each other in love.

\section{F-stop: organisations and choice}

To move the f-stop of this essay on a notch to take a tighter focus, consideration is now given to organisations as microcosms of cultural and biological systems. The poet Whyte (2001, p.163) exhorts his readers to find an identity in their personal histories who represents freedom, 'someone who seemed to exude freedom by the way they lived, who was not a slave 
to all the truths repeated so easily by others, who had a breath of spontaneity in their lives'. What of the exile in an organisation who lives freedom in choosing not repeat the 'truths' of the habitus? Whyte (2001, p.164) carefully points out that the current poverty and hopelessness in organisational life stems from a 'lack of time and spaciousness and wherewithal to gain it back from the entities that demand so much from us in order to ensure our spending power, our promotions, and our participation', but also that the corporate masters of the market are not 'abstracts working their evil ways on us. We ourselves helped form them and helped to create them in our image'. In other words, people collude in their shaping through collaboration but there can come a point where the balance of power lies without. People may find themselves unable to resist the 'mud' of their own making, as Whyte (2001) puts it. He talks about imprisonment as the stage where no new strategy can free and no new organiser can reorganise. Liberation can only come through reimagining 'to reshape ourselves in conversation with the world' (Whyte, 2001, p.201). For those in organisations who choose exile as the path of reimagining participation, seeing through the habitus may enable new images of organisations other than the tightly controlled vertical and hierarchical model of the factory upon which markets in their supply and demand depend.

One imaginative and loving choice coalescing out of the flow of air is to see organisations as living, adaptive systems (Stacey, 1996). In complexity theory, reimagining participation is to choose resistance to any solid given but also to engage in ongoing autopoiesis, or self-creation and organisation (Bauman, 2000). Let out of the 'stiff armour of .... artificially constructed ethical codes'(Bauman, 1993, p.35), the exile's morality is released into the air and is without principle - without solid, socially established foundation - and thus is re-personalised (Bauman, 1993). The dignity of a self-created purpose and destiny empowers organisation, as an expression of relationship amongst exiles, chosen to flow and learn rather than reference to habituated practices that enclose and slowly starve the spirit (Whyte, 2001). In contrast to the conditioning of single loop learning that notes environmental change and accommodates behaviour to established norms and schema, the double loop learning of adaptive systems goes further to reimagine schemas and generate innovative behaviours (Stacey, 1996) in response to the initial change. For exiles, such learning has no foundation or simple causeand-effect linearity and is an adventure into the unknown and the messy unpredictability of complexity. Organisations as systems tend to entropic stability as energy is bound up in the schematics of the habitus and people's collaboration in maintaining it. Consumers in the knowledge economy, as it is now enacted, are an example of this. For all their apparent choice and change, little significant really does alter. 
Exiles, on the other hand, are like free radicals, choosing to question the system and provoke new responses that liberate energy and keep it circulating in a flow of evolving change and increasing fitness in the landscape. In their responsibility to self and other, they create a little chaos in choosing to change the schemas by which they organise but also choose to adaptively change their behaviour to improve the relational orderliness and thus emergent social outcomes for all. As Marion (1999, p.xiii) points out, the unpredictable and chaotic nature of free will creates novelty, but 'novelty is the author of new order'. A temporary increase in disorder can be contained by an also free-willed, moral agreement 'to cooperate for the common good and abandon all competitive behaviour' (Stacey, 1996, p.113). This edge-of-chaos dynamic is in contrast to the permanent chaos of the competitive marketplace where individual monetary profit is the one strange attractor necessary at all costs. No other form of order can be entertained. In the organisational learning of exiles, they continually make moral choices to develop a better way of living and produce the fluid knowledge that motivates an emergent shadow economy. In coming to influence the economy through selforganised creativity, exiles alter the balance of power in moving from the powerlessness of consumption to the power of love, being 'for the other' and producing currency of social and cultural capital, and public rather than privatised goods, to become stakeholders of a different kind in the knowledge economy. More will be said at the end about the relationship of knowledge and choice, but for now, the organisation of schools will be examined from a complexity theory point of view and implications raised for choices for change.

\section{Focal point: schools}

In deterministic, that is, single-loop feedback systems, as are prevalent in current organisations including schools, learning is about accommodating to change and 'tweaking' for best fit to circumstances. The system is 'in charge', usually at some level higher up a hierarchy. The curious thing as far as choosing change and learning is that, as Stacey (1996, p.71) observes, '....we can get such a system to do what we want only if what we want is an endless repetition of what it has already done'. The capacity for significant change is limited, in the same way as it is for today's consumers. For example, with reference to the organisation of schools in particular, and of teachers and students, Sarason's (1990) view is that educational reformers do not talk about changing the system, but speak in terms of cosmetically improving schools or the quality of education so there is change by addition but 
little deep change. He is critical of reforms that are based on accepting the system as it is and notes that, 'The problem is not what we do but how we think, how to take seriously the idea that there is a universe of alternative explanations for past failures of reform' (Sarason, 1990, p.xi). In other words, the problem stems from blindly accepting the habitus as given, without thinking about how else the world and systems might be configured. In not 'seeing' or deeply understanding the real and dynamic complexity of organisations like schools, education systems are locked into their own ground-hog days, unable to choose to change because they cannot entertain that choices to change exist and can be created.

In line with the classic simile of the forest and the trees, Sarason (1990, p.42) emphasises that:

'...comprehending a social system, large or small, requires a drastic alteration of the way one literally looks and acts in regard to the system: you are aware of the parts, you do not ignore them, but your prime task is fathoming the processes and rules sustaining the system'.

A critical item on Sarason's agenda in this prime task is to examine power relationships within schools and education systems. To his mind, while this is avoided, 'the more things change, the more they will remain the same' (Sarason, 1990, p.5). While energy and thus power is locked into the habitual organisation of schools and schooling, circular single-loop learning only works to maintain the system in traditional ways. However, self-empowering exiles on the loving path of emancipation can choose other than the apparently rigid bonds of habitus and work to free up the energy of the solid system, loosing it to the air and to change. This is possible because exiles choose a different kind of learning that can entertain the novel and imagine the new, weaving innovative and gossamer webs of relationships. Like the spider's web, they float in the air but are light, strong and always open to reweaving as circumstances change.

Exiles employ a double loop learning that is adaptive. In this more complex style of change, they choose to change the schema and systems that shape webs of power and to generatively change their behaviour, creating new patterns of relationships. Like the exiles in the earlier story, today's exiles in education recognise that they have to work together. It is an interesting conundrum that while change can only be chosen in individuals (Carr, 1996), choice can only be enacted with others. The exile is a social being, affected by but also effecting society, so all choice for change is interactive (Marion, 1999; Stacey, 1996) and involves the individual-in- 
relations. In the past war, being morally 'upright' meant refusing to surrender to the invader, but also refusing to surrender to the fear and hunger of the self alone and actively working 'for the other' in recognition that self and other were inescapably entwined. Similarly today, the schematic systems of organisations like schools are woven of relationships amongst people, and exiles who would 'thrive' more than simply 'survive' strive to learn to live together in productive and ecologically sustainable 'forest' ways that are beyond individualistic 'tree' ways. They recognise that in choosing to pool their energy, their power for change is greater than in acting alone. In learning organisations on the edge of chaos, liberation is not pre-determined but is an act of ongoing self-determination as exiles learn together to creatively adapt and thus evolve. In the little chaos of weaving new webs of relationships that is adaptive learning, Stacey (1996, p.163) notes that ' ...people can hold the anxiety of creative destruction because of the relationships of trust within the group' and because they operate within a 'good enough holding environment', which for exiles is their moral stance of being 'for the other'. In schools, choosing adaptive change means choosing to trust others and to cooperate with others. This is different from blind collaboration with the habitus; this is a self-aware choosing to operate with others to learn ways of relating and autopoietically organising that encompass power sharing through mutual trust. This is conquering freedom collectively, as Bourdieu (1990) put it.

The case - and the self-chosen responsibility - for choices in changing schools, then, lies with the moral individuals in education who journey into exile in the company of others to develop schools as complex adaptive systems that learn their way into consensually diversified, alternative futures. As they are, Fullan (2001, p.16) reveals schools as being 'a much more conservative agency for the status quo than a revolutionary force for transformation' and that '...existing strategies will not get us where we need to go, if we want large-scale, lasting reform' (Fullan, 2001, p.268). On perhaps a more hopeful note, he also notes that 'educational change depends on what teachers do and think - it's as simple and as complex as that' (Fullan, 2001, p.115). Change comes down, in essence, to the choices of teachers and other educators, in so much as they ultimately make the choice to become exiles from the existing habitus and to interact with and for each other to learn and create new patterns of relationship and power.

For Fullan (2001, p.124), as with the researchers noted above, interactivity is important because such choices for significant change come about 'only through a process of personal development in a social context'. In mutual challenge and support, exiles accept the personal and shared responsibility of change and claim the freedom to recreate education. When 
teachers practise together, for example, in professional learning communities and hold each other in trust, they produce a pressure on themselves and the school system that builds up to edge-of-chaos states. These provoke action to create new and unpredictable schema that require new behaviours to regain balance in an ongoing change process (Fullan, 2001). Rather than being passive consumers and even victims of change forces, as Fullan (2001) puts it, self-empowered educators with a moral purpose and passion (Fullan, 2003) can choose to be dynamic perpetrators of change or, in other words, forces for change. In professional learning communities that are learning organisations (Fullan, 2001), educators co-evolve (Carr, 1996) in choosing to use their energy to create knowledge and thus significant and substantial change. To look more closely at this actual process of making choices that create change and thus learning and knowledge, the focus will now move into the domain of psychology.

\section{F-stop: psychology and choice}

According to Stacey (1996), for organisations to develop over time, the feedback process that individual agents/exiles must engage in to create change has three elements: discovering, choosing and acting. The discovery element is about more accurately sensing the states of the parts within the organisation and of the parts of the larger environment they are in contact with. Choosing is that element wherein agents/exiles select a response from universal and/or specific tables of rules or proactively elect to create new rules. In the minimalist, single loop model of change, selection from existing rules works to reproduce the system but increase its efficiency. In a more radical, double loop model, agents/exiles notice the habitus and elect instead to produce new rules aimed at creating a more effective system. Acting, lastly, is the process of implementing changes through altered behaviour. In his analysis of change, Argyris (1970) similarly suggests three elements in a model that has coherence with that of Stacey (1996). His elements are information, choice and commitment, with the overall process being that, 'Problem solving requires valid information. Decision making requires choices and decision. Implementation requires internal commitment' (Argyris, 1970, p.37). Put together, the change process can be seen as involving finding whatever it is that is needed to inform and solve problems stimulated by the sensing of dissonance - such as exiles experience in seeing through the veil of habitus; a choosing amongst schematic and behavioural options in making a decision about how to respond - for exiles, to conquer freedom; and then committing to and enacting the chosen response - as conscious and liberating emancipation. 
Importantly, Argyris (1970) states that unless agents as exiles can generate valid information and options, can choose freely and can commit to choices, and unless they can bring these conditions about with their own behaviour, changes in organisations and control systems will not succeed. The case with consumerism and passive collaboration, whether in the economy in general or in organisations like schools, is that information may be insufficient or superficial; options may be hidden either intentionally or through lack of awareness and ability in lifting the veils of habitus and generating alternatives; and agents may not be able by their free will to choose, decide and commit to action. However, to Argyris (1970, p.129), 'the door to effective change is locked from the inside'. The real effect of externally ordering change is to place agents in positions of psychological failure because the reference point of wisdom is not the agents' own. The exiles of the story would have failed themselves, failed in their moral stance of being upright, if they had accepted the dominant agents' ordering of their world. For those in schools who suffer systemically mandated change, the result is similar. Teachers and other educators can come to feel disempowered when they live in a story that is not their own and feel as though they have failed in some way. The route to regaining power is to become activist more than agent through exile from the familiar and habitual. As has been demonstrated earlier, the light and airy flow of an exile's selfauthorising storyline can be a powerful force for change.

From another perspective, Glasser (1998, p.5) explicates the more solid operational premise of imposed change using external control psychology as being to, 'Punish the people who are doing wrong, so they will do what we say is right; then reward them, so they keep doing what we want them to do'. He notes that coercion has been around so long that is considered common sense (Glasser, 1998). In today's economy, it is an unquestioned aspect of the habitus to try to get one's own way, even if it is at expense of others. In Glasser's (1998) view, the coercion of external control psychology works insidiously in a number of ways. Most obviously, it allows powerful dominating agents to get what they want. However, it also works for the powerless in a twisted way. They 'experience it working on them and live in hope that they will eventually be able to use it on someone else' and 'believe they are not free to choose otherwise' (Glasser, 1998, p.6). To resist would be to end up in a worse predicament. Yet, to collaborate with coercion is a choice. According to Glasser (1998, p.3), 'we choose everything we do, including the misery we feel'. To him, the moral question is, 'How can I figure out how to be free to live my life the way I want to live it and still get along with the people I need?' (Glasser, 1998, p.5). Glasser (1998) suggests using choice theory as 
an internal control psychology. In this, the exile does not give power to the apparently given, but accepts responsibility for each and every choice within a moral framework of being for self-and-other. To unlock the door to change, then, implicates the exile in consciously accepting responsibility to get the information needed to generate options for choices, to choose wisely according to personally and communally developed 'tables of rules' such as mutual trust and respect, and to commit to enacting those choices in change.

It is by far the easier option - and choice - to go along with it all: to consume, to coerce, to be powerless, to blindly accept the habitus. What does it take to take that first step into exile, into self-empowerment and emancipation, and into being 'for the other'? According to complexity theorists and psychologists, the way 'down' is the way 'up'. When disintegrating to the edge of chaos, the holding environment of a company of cooperating conspirators can contain the anxiety provoked by complex learning (Stacey, 1996). That is why, as Fullan (2001) notes, professional learning communities work for teachers and other educators. As the bonds of the habitus loosen, people become disconnected (Glasser, 2000) and lose all pattern to a point of being in a depressive state (Stacey, 1996). However, it is at that very edge where the attractor of love can barely contain the anxiety that the creativity of change kicks in. In the exile's way, change involves a choice of pain, that of anxiousness and uncertainty, in order to be able to make other choices and create change. The exiles of the story chose to live with that pain to gain their freedom to choose. While today's exiles might not live in such heightened awareness on the edge of life or death, they are aware that every choice they make has a consequence they are responsible for and they commit to it freely. They can live with the pain so freedom can be enjoyed. In an ambiguous world, that awareness and moral acceptance of choice and personal responsibility for social actions defines identity more than any external ethics or coercions could. Whyte (2001) concludes that personal identity is a function of ability to pay attention to the world. The habitus is largely unsensed by most, but it is in the identity of exile that people, including teachers and students, can learn to attend to what is and what might be rather than what appears to be. Little attention means little real existence (Whyte, 2001) because little conscious choice is made about the kind of life that is lived and the kind of world that is created. In the words of a popular song, ironically about schools and schooling, 'you've got to wake up and pay attention' in order to have choices for change. With this, the focus now comes into the domain of biology to look more into the physiology of awareness and attention, with students as the exemplar. 


\section{F-stop: biology and choice}

In the human process of choosing and thus making a decision, it has been noted above that one option is selected from a range of potential choices, with these being either self-generated or given. At each choice point, one path to the future is elected at the expense of others, that path creating a particular reality while denying others from emerging. From a biological point of view, the consequences of choice paths influence fitness in an environment and drives natural selection. However, rather than studying the outcomes of choice and changes after the fact, the attentional and informational antecedents influencing choice are of interest here in promoting learning because they concern the change potentials that occur within the process of choosing. In the human brainbody, Slywester (2003) reports non-technically on the three functional systems that regulate attention. First there is an 'orienting' system that disengages the current focus and shifts attention to a new challenge. The higher the contrast of the new situation, the greater is the emotional arousal and the likelihood of attention shifting. Steady states, gradual changes and subtle differences are ignored or merely monitored because they don't carry a sense of immediacy and thus survival value. In other words, gross change attracts more attention and nuances can be lost. As a hard-wired response to changing and possibly dangerous environments, this had biological value in earlier times but choosing to respond to subtleties may have more survival value in this day and age. In today's economy, competition for attention and spending is fierce and, in such a world of ever more varied 'bells and whistles' to attract customers, consumers with their transient wishes can easily be blinded by the glitter of the monetary attractor. A concern in schooling, therefore, needs to be the cultivation of attention to detail and the social and cultural information it contains, so the deeper learning opportunities inherent in subtleties are not glossed over.

The second 'executive attention' system foregrounds the new challenge, separating it from the bed of more consistent background information, and uses memory to seek to identify its nature and determine its significance. Memory is an internal form of habitus that, like attention to gross environmental change, is wired for survival. However, for the exile whose concept of survival encompasses being for the other, a conscious effort can be made to interrogate memory, to mentally step back to give the wait time needed to generate other than reflexive responses. If the focus of the executive attention system cannot elicit what the exile decides is an appropriate established response, the challenge is raised to a higher level of consciousness, alternative options generated and an optimal response chosen. Working memory is important here as it can hold a few choice options for review, but its real value in 
learning is its limited capacity. It forces the combination of 'related bits of information into larger units by identifying similarities, differences, and patterns that can simplify and consolidate an otherwise large and confusing sensory field' (Sylwester, 2003, p.45). Such pattern building and making sense contributes to the development of longer term memory. Whilst young children lack the frontal lobe development in the brain to do such abstract processing and rely on adults to model appropriate responses, adolescents need to be confronted with challenges that need more than reflexive or habitual responses in order to begin developing their self-aware thinking and memory abilities. In Slywester’s (2003, p.46) words, schooling should provide 'many options that require participants to make choices that they can later reflect on to determine the wisdom of their choices.' Equally, it should provide opportunities for exile, that is, for students to gather adequate information from memory or by self-generation, as in Argryis' (1970) problem solving, to make other than habitual choices in decision making.

'Vigilance' is the third system involved in regulating attention. It does the opposite of the orienting system in that it works to maintain and sustain focus by ignoring small changes in the environment that could distract attention. This system is particularly useful in supporting attention to several non-competing events simultaneously. In developing attentional systems and thus ability to sustain learning, Slywester (2003, p.47) suggests the creation of 'activities that enhance students' ability to decide whether to maintain a current attentional focus and then to make intelligent choices about short- and long-term attentional tasks.' In other words, he means activities that incorporate choice in what to do and in what level of commitment to make in attending to it. Providing opportunities for choice develops the ability of conscious vigilance in choosing how to regulate attention. In having high distractive value, the everchanging glitz of today’s economy does little to foster vigilance. Consumers have many competing choices, most of which are so shallow and rapid as to create an apathetic blur in students' minds. In learning activities that require more spacious and detailed information gathering and problem solving, students have a genuine chance to be more vigilant, particularly of the less obvious, and thus to become more aware of the habitus. In sustained, deep and reflective learning driven by choice and self-responsibility, the exile is in a better position to activate emancipation.

Together, the three-part attention system works across the arousal-focus spectrum. In young adolescents, attentional behaviour is still largely reflexive and impulsive but middle schooling practices, in particular, that incorporate opportunities for student choice can support front 
brain development and the eventual emergence of increasingly reflective young adults. Training young people to sense detail can fine tune the orientation system and open attention to a greater breadth of opportunities from which they can choose to learn. Setting up problems that require students to generate options and which allow the choice of novel responses exercises the executive attention system and promotes deeper, more complex learning and longer term memory. Developing learning environments that minimize distraction and thus support vigilance gives students opportunities to consciously choose their focus and to sustain their learning through reflection.

The middle years of learning between childhood and adulthood are a time of considerable changes - an exile in itself - for adolescents and, from the biological perspectives explained above, schooling can influence the nature of those changes and the consequent nature and outcomes of adult life. A curriculum as given and a teacher who delivers have little value in increasing students' resilience and adaptivity in a changing world. There is no known process for a sponge-like transferring of information from the environment to the student per se, but there is a case for selection and for the activity-induced synaptic growth and development (LeDoux, 2002) of learning. As has been demonstrated, actively promoting opportunities for student choice broadens and deepens attention and focuses learning and, importantly, supports innovative responses to problems and thus creative realities. The exile of adolescence can be a positive and liberating journey of emancipation, of going away from the innocent acceptance of childhood and into an empowered adulthood. In essence, changing the choice-making opportunities of students can increase their ability to make choices for change in their future.

Ecologically speaking, changing choices for students implies changing schooling. In his work, Slywester (2003) has sought to draw analogies between biological brain function and cultural classroom function in order to shape more organic views of learning. He notes that cultural transmissions - dubbed ‘memes’ by Dawkins (1989) and similar to Bourdieu’s (1990) 'habitus' - such as schooling can be as persistent as genetic transmissions in replication. This is so much so that, according to Carr (1996), culture has been developed as 'an extension of evolution itself'. Schooling, in fact, was originally introduced as a replication technique but with solid melting into air, today it is needed as an adaptive technique. If it is to be based on a biological instead of an industrial model to support choice for change, schooling itself must radically adapt. 
Through a biological lens, Carr (1996) argues for a new model of organisation in which organisational theory is moved out of pre-Darwinian ideas of a divinely ordered universe and into today's world where indeterminacy and constant change are accepted as the realities of evolving life. He emphasises ecological interdependence by emphasizing coevolution and notes that every organism's survival is related to what every other organism is doing: '...organizational choices are meaningless apart from choices made by competitors, customers, government bodies, and all the other elements of their environments' (Carr, 1996, p.4). To give students more choice in support of better learning and greater competence as an adult means that other choices must be made by all those involved in schooling if there is to be living and learning organisation. However, Carr is careful to explain that despite the complexities of organisational systems, only individuals can actually choose to change. In line with Slywester's (2003) elucidation of the role of the executive attention system in developing novel solutions, he emphasises the conscious creativity of human being and suggests that generating and harnessing the creativity of the members of an organisation supercharges it ability to evolve. Creative choices in students are related to the sentient and intentionally creative choices - that change potentials into actualities - made by teachers, parents, administrators, policy makers and all those involved in schooling. A future meme or pattern-making of schooling could be cultural renewal instead of cultural reproduction.

\section{A new focus: choice for a change}

The focal points of this essay have become increasingly tight in moving from the broad scope of society to the attention and learning of young people and their choices for change as active citizens in making a better future for themselves and others. The time has come now to relax the focus to take in the big picture and to reflect on the legacy of choices, a 'forest' that individual 'trees' often fail to notice. With a philosophical bent, the question is asked: What do people today, and what will young folk tomorrow, choose to be the nature of the knowledge economy? In exile, it could be said that the view is more detached and a relaxed but attentive focus is able to take in the peripherals; in other words, to see the forest for the trees and the social outcomes of choices made by individuals. In today’s knowledge economy, Barber’s (1995) ‘money hooligans’ buy and sell knowledge for personal monetary gain with scant regard for social and cultural effect. The kind and quality of knowledge being bartered is largely irrelevant; just so long as it makes money. In being for the other, however, the exile has a wider and more inclusive focus and may consider making choices that give preferential 
support to certain kinds of information and knowledge that have communal as well as individual value. They may, for example, make the moral choice of love to value knowledge that has high social, cultural and environmental worth more than monetary worth. Thus, they might consistently make loving choices that emancipate knowledge and result in changes in how the knowledge economy is constituted. The potential exists for the knowledge economy to be powered by social and cultural capital rather than purely monetary capital.

In schools, the further questions could be asked: Does education support young people in making choices for a change? Will they have the ability, in the world in which they live, to choose the nature of knowledge and how it is valued? Carr (1996) talks about knowledge as the mental models that are used to do what has to be done to accomplish chosen purposes. As schooling stands, knowledge is largely given as being the ways of the world, as they have always been presumed to be, and students are asked to accept this mental model and accommodate to the habitus of cultural replication. The role and purpose of exiles today - and hopefully they may be found in 'learning' schools in the guise of teachers and other educators - is to dissolve that solid model of knowledge to create an adaptive knowing that is lighter and more flexible. Exiles now are similar to those of the long ago story of my father and his people. If they choose choices for change in encouraging each other and young people to move beyond collaboration, they move into the free-flowing adaptive cooperation and coevolution that creates new knowledge and a new world.

From a biological point of view, natural selection picks up on genetic mutations (changes) that make for a better fit in a world that is always changing. For human beings evolving in society, the situation is the same in that social and cultural mutations that adaptively increase fitness in the changing world through creating new knowledge will self-select for emancipation and survival of the species. On the other hand, knowledge that does not change with the times self-selects itself out of the evolutionary process. If educators, schools, and society at large persist with solid and outdated mental models to underpin knowledge, young people will be selected out of futures of their choice. Knowledge needs to evolve with the world; in fact, the liberation of knowledge through emancipative choices for a change made by self-and-other-aware exiles needs to drive the economy. In the knowledge economy, who should be in the driver's seat? Should it be the financial economists who barter knowledge to the highest bidder or should it be the social economists and knowledge makers, comprised of exiles who move beyond the habitus to come home to a consensual demos bound by love, who determine what is worthwhile to know and what value it has in social and cultural terms, 
more than individualistic monetary terms? Which mental models would be most useful for today's young people to be able to truly choose their future? If the moral purposes are to be social and communal development, mental models should be chosen and knowledge created to accomplish those purposes. One choice for a change could be a knowledge economy that trades in love and being 'for the other'. The choice, like tossing dice, is all up in the air. Are our young people and their future worth the risk? 


\section{References}

Argyris, C. (1970). Intervention theory and method: A behavioural science view. Reading: Addison-Wesley.

Barber, B. R. (1995). Jihad vs. McWorld. New York: Times Books.

Bauman, Z. (1993). Postmodern ethics. Oxford: Blackwell.

Bauman, Z. (2000). Liquid modernity. Cambridge: Polity.

Bauman, Z. (2001). The individualised society. Cambridge: Polity.

Bauman, Z. (2003). Liquid love: On the frailty of human bonds. Cambridge: Polity Press.

Berman, M. (1988). All that is solid melts into air: The experience of modernity. New York: Viking Penguin.

Bourdieu, P. (1990). In other words: Essays towards a reflexive sociology. Stanford: Stanford University Press.

Carr, C. (1996). Choice, chance and organizational change: Practical insights from evolution for business leaders and thinkers. New York: American Management Association.

Dawkins, R. (1989). The selfish gene. New York: Oxford University Press.

Friedman, L. (1999). The horizontal society. New Haven: Yale University Press.

Fullan, M. (2001). The new meaning of educational change (3rd ed.). New York: Teachers College Press.

Fullan, M. (2003). Change forces with a vengenance. London: RoutledgeFalmer.

Glasser, W. (1998). Choice theory: A new psychology of personal freedom. New York: HarperCollins.

Glasser, W. (2000). Reality theory in action. New York: HarperCollins.

Hargreaves, A. (2003). Teaching in the knowledge society: Education in the age of insecurity. New York: Teachers College Press.

LeDoux, J. (2002). Synaptic self: How our brains become who we are. New York: Viking Penguin.

Marion, R. (1999). The edge of organization: Chaos and complexity theories of formal social systems. Thousand Oaks: Sage.

Ogilvie, D. (2004a). The next world: Anarchy now. Flaxton: Post Pressed.

Ogilvie, D. (2004b). Personal communication.

Sarason, S. B. (1990). The predictable failure of educational reform: Can we change course before it's too late? San Francisco: Jossey-Bass.

Stacey, R. D. (1996). Complexity and creativity in organizations. San Francisco: Berrett Koehler.

Sylwester, R. (2003). A biological brain in a cultural classroom (2nd ed.). Thousand Oaks: Corwin Press.

Tester, K. (2004). The social thought of Zygmunt Bauman. Basingstoke: Palgrave Macmillan. Whyte, D. (2001). Crossing the unknown sea: Work as a pilgrimage of identity. New York: Riverhead Books. 